Susan Haley MD FRCPC, Gerald Edelist MD FRCPC, Gordon Urbach MD FRCPC

\title{
Comparison of alfentanil, fentanyl and enflurane as supplements to general anaesthesia for outpatient gynaecologic surgery
}

\begin{abstract}
We compared two narcotici $\mathrm{N}_{2} \mathrm{O}$ anaesthetic techniques and an inhalational anaesthesia/ $\mathrm{N}_{2} \mathrm{O}$ technigue for ontpatient surgery in 59 women undergoing short gynaecological procedures. All patients received droperidol $0.625 \mathrm{mg} N$, thiopentone and 70 per cere $\mathrm{N}_{2} \mathrm{O}$ in $\mathrm{O}_{2}$ plus either alfentanil ( $15 \mu \mathrm{g} \cdot \mathrm{kg}^{-1}$ ). fentanyl $\left(1.5 \mu \mathrm{g} \cdot \mathrm{kg}^{-1}\right)$ or enflurane. The narcotics were given in a double-blind fashion and all anaesthetic techniques were assigned randamly. Cardiorespiratory parameters remained stable in all groups, with few clinically important changes occurring. Recovery was significantly faster in the group receiving alfentanil, with the time to respond to verbal commands and the time to establish aleriness significantly faster than with either fentanyl or enflurane. All techniques provided satisfactory ancesthesia; however, the patients receiving alfentanil had significantly more adverse events than those receiving fentanyl.
\end{abstract}

\section{Key words}

ANAESTHESIA: general, outpatient; ANAESTHETICS, INTRAVENOUS: alfentanil, fentanyl; ANAESTHETICS, INHALATIONAL; enflurane.

From The Department of Anaesthesia, Mount Sinai Hospital, 600 University Avenue, Toronto, Ontario, M5G 1X5.

Address correspondence so: Dr. Haley.
Alfentanil is a new narcotic analgesic with a chemical structure similar to that of fentanyl. Alfentanil may be particularly suited for outpatient anaesthesia because of its rapid onset, short duration of action and fast recovery. To determine whether alfentanil offers advantages over drugs currently used in outpatient anaesthesia, we compared alfentanil to fentanyl as adjuncts to thiopentone/ $\mathrm{N}_{2} \mathrm{O}$ anaesthesia. We also compared these two techniques to an enflurane $/ \mathrm{N}_{2} \mathrm{O}$ anaesthetic, since the latter is a common technique for short procedures in our institution.

\section{Methods}

After approval by the Human Subjects Review Committee at the University of Toronto, informed consent was obtaincd from 59 unpremedicated females, undergoing elective minor gynaecological surgery as outpatients. The patients were ASA physical status Class I or II and between the ages of 18 and 60 . Before surgery, a medical history, physical examination and appropriate laboratory tests were obtained. All patients were fasted for at least eight hours and randomly assigncd to one of three groups: Group A - alfentanil/ $\mathrm{N}_{2} \mathrm{O}$; Group $\mathrm{F}$ - fentanyl $/ \mathrm{N}_{2} \mathrm{O}$; Group $\mathrm{E}$ - enflurane/ $\mathrm{N}_{2} \mathrm{O}$. There were 20 patients in each of the narcotic groups and 19 in Group $\mathrm{E}$.

An electrocardiogram was monitored continuously. Arterial blood pressure (systolic, diastolic and mean) and pulse rate were recorded with a Datascope ${ }^{3}$ oscillonometric, non-invasive monitor with recorder. Respiratory rate (RR), complications and recovery data were recorded by a single trained observer, who was blinded to the identity of the narcotic but not to the inhalational anaesthetic. Vital signs were recorded on arrival in the operating room, immed iately after administration of the test drug, immediately after surgical stimulation and every five minutes thereafter during the procedure. After an intravenous 
cannula was inserted on arrival in the operating room, droperidol $0.625 \mathrm{mg}$ was given IV to all patients to minimize postoperative nausea and vomiting. ${ }^{1-3}$ After administration of droperidol, the patients in Group $A$ were given alfentanil $15 \mu \mathrm{g} \cdot \mathrm{kg}^{-1}$ and those in Group $F$ were given fentanyl $1.5 \mu \mathrm{g} \cdot \mathrm{kg}^{-1}$. All narcotics were administered slowly over $20-30$ seconds in a double-blind fashion. Two minutes after the narcotic, thiopentone (3-5 $\mathrm{mg} \cdot \mathrm{kg}^{-1}$ ) was administered in incremental doses intravenously until the patient was anaesthetizcd. The onset of anaesthesia was determined by the loss of eyelash reflex. In the alfentanil and fentanyl groups, anaesthesia was maintained with 70 per cent $\mathrm{N}_{2} \mathrm{O}$ in $\mathrm{O}_{2}$. Additional doses of thiopentone ( $50 \mathrm{mg}$ increments up to a total dose of 500 $\mathrm{mg})$, or smaller increments of alfentanil or fentanyl $\left(5-10 \mu \mathrm{g} \cdot \mathrm{kg}^{-1}\right.$ or $0.5-1.5 \mu \mathrm{g} \cdot \mathrm{kg}^{-1}$ respectively) were given intravenously as needed to maintain satisfactory anaesthesia and surgical conditions.

Supplemental anaesthesia was given in accordance with signs of light anaesthesia and/or patient movement. If the patient received a total of $500 \mathrm{mg}$ of thiopentone and the maximum dose of narcotic (alfentanil $30 \mu \mathrm{g} \cdot \mathrm{kg}^{-1}$; fentanyl $5 \mu \mathrm{g} \cdot \mathrm{kg}^{-1}$ ) and if further anaesthesia was needed, enflurane or isoflurane was administered with the anaesthetist using the drug of his/her choice.

The patients in Group E (enflurane) did not receive any narcotic. After induction with thiopentone, enflurane was administered with $\mathrm{N}_{2} \mathrm{O}$ in $\mathrm{O}_{2}$ in the concentration deemed clinically necessary. The protocol was otherwise the same as the narcotic groups.

At the end of the procedure, the anaesthetic was discontinued and the patients were transferred to the Recovery Room. Supplemental oxygen was administcred by face mask and vital signs were recorded every 15 minutes for at least one hour. The patients were assessed by the same blinded observer for: (1) the time to recover eyelash reflex; (2) the time to respond appropriately to verbal commands; (3) the time to establish alertness (orientation, simple addition, and date of birth); and (4) the time to discharge. This obscrver remained with the patient until the assessment was completed. Immediately prior to discharge, the patients were questioned about perioperative awareness and amnesia, and asked to give their impression of the anaesthetic experience. Further, the patient's level of pain and need for postoperative analgesics were recorded as were all intra- and postoperative events, such as chest wall rigidity and nausea and vomiting. The anaesthetists were also asked to evaluate the patients' induction, intraoperative course and recovery.

Data are presented as mean value and standard error of the mean (SEM). Recovery data were evaluated using the Kruskal-Wallis Test for overall significance, with the Mann-Whitney U Test, $p$ value modified according to Ryan $^{4}$ for pair-wise comparisons. Proportional data were evaluated using the Chi-square or Fisher's fest, as required. Differences in cardiovascular variables were determined using the repcated measures two-way analysis of variance. Between group differences were based on change from control. Use of "significant" denotes statistjcal significance at the five per cent level (two-tailed).

\section{Results}

Demographic data for all three groups showed no signifjcant between-group differences. The majority of patients underwent a dilatation and curettage (D\&C), and were ASA physical status I or II. The mean ages of the three groups ranged from $32-42$ years. The average duration of surgery and anaesthesia was less than ten minutes.

The mean initial alfentanil dose was $15.3 \mu \mathrm{g} \cdot \mathrm{kg}^{-1}$ with four patients requiring supplemental doses (Table l). The initial mean dose of fentanyl was $1.5 \mu \mathrm{g} \cdot \mathrm{kg}^{-1}$ with three patients requining supplemental doses. The initial thiopentone dose was similar in all groups. Four patients in Group A, two in Group F and none in Group E required supplements of thiopentone. The induction was rated as good or satisfactory in all patients in all groups, except for one in Group $\mathrm{E}$ which was rated as bad.

The intraoperative cardiovascular variables are summarized in Figures 1 and 2 . With the exception of diastolic blood pressure in Group $E$, all treatments showed significant $(p<0.05-p<0.001)$ within group changes in the cardiovascular variables assessed. Group E showed a significant $(\mathrm{p}<0.05)$ decrease in systolic blood pressure

TABLE I Drug dosages (mean)

\begin{tabular}{llll}
\hline Drug & Inisial dose & $\begin{array}{l}\text { Patients requiring } \\
\text { supplemental doses }\end{array}$ & $\begin{array}{l}\text { Total dose in patients } \\
\text { requiring supplements }\end{array}$ \\
\hline Alfentunil & $15.3 \mu \mathrm{g} \cdot \mathrm{kg}^{-1}$ & $4(20 \%)$ & $25.4 \mu \mathrm{g}^{-\mathrm{kg}^{-1}}$ \\
Fentanyl & $1.5 \mu \mathrm{g} \cdot \mathrm{kg}^{-1}$ & $3(15 \%)$ & $2.1 \mu \mathrm{g} \cdot \mathrm{kg}^{-1}$ \\
Thiopentone & & $4(20 \%)$ & $5.2 \mathrm{mg} \cdot \mathrm{kg}^{-1}$ \\
Group A & $4.5 \mathrm{mg} \cdot \mathrm{kg}-1$ & $2(10 \%)$ & $5.9 \mathrm{mg} \cdot \mathrm{kg}^{-1}$ \\
Group F & $4.5 \mathrm{mg} \cdot \mathrm{kg}^{-1}$ & $0(0 \%)$ & $\mathrm{na}$ \\
Group E & $4.4 \mathrm{mg} \cdot \mathrm{kg}^{-1}$ & & \\
\hline
\end{tabular}




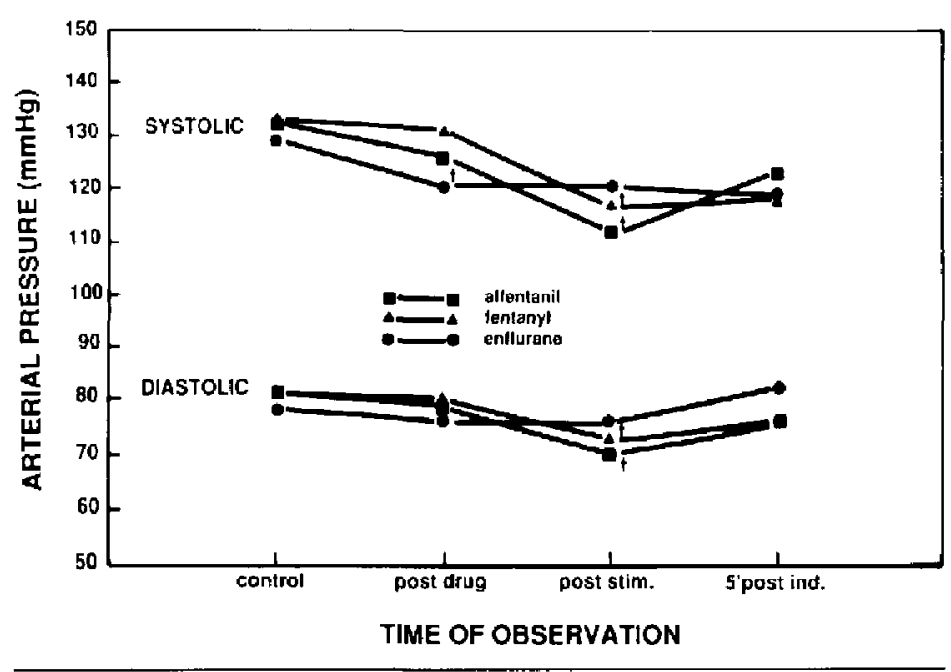

FIGURE 1 Arterial blood pressure measurements ( $\dagger$ indicates signiticant change from control).

at the "post drug" observation with no further decrease thereafter. Both Groups $A$ and $E$ showed a significant ( $p$ $<0.001)$ decrease in systolic pressure "post-surgical" stimulation, with diastolic pressure also decreasing significantly. Heart rate increased significantly in the Groups $A$ and $E$ "post-drug" and returned to control value only in Group A (remained elevated with enflurane). Group F had a sigmilicantly lower heart rate "pust-surgical" stimulation. Respiratory rate slowed significantly with all treatment groups but retumed to control after surgical stimulation in Group E only. At the "post-surgical" stimulation point, systolic blood pressure was significantly lower in Group A than in Group F, heart rate with enflurane was significantly higher than with fentanyl, and respiratory rate with both alfentanil and fentanyl were significantly lower than with enflurane. Postoperative cardiovascular variables showed no significant within or between treatment differences.

The recovery data (Table II) all indicate that patients in Group A were alert and responded to verbal commands significantly faster than patients in either the fentanyl-or enflurane-treated groups. All patients were amnesic for the operation. Recovery was judged to be good or satisfactory in all patients in all groups.

Table III summarizes the adverse intra- and postoperative events which occurred. Two patients in Group A had particularly troublesome reactions: one patient moved and vocalized at the start of surgery, and when given more narcotic and thiopentone, developed chest wall rigidity and apnoea. This patient was ventilated manually with a

TABLE l R Recovery data

\begin{tabular}{|c|c|c|c|}
\hline & Affenuanil & Fentanyl & Enflurane \\
\hline $\begin{array}{l}\text { Time (min) to respend to verbal } \\
\text { commands *(mean } \pm S E M)\end{array}$ & $2.8 \pm 0.54$ & $4.7 \pm 0.73$ & $8.1 \pm 0.84$ \\
\hline $\begin{array}{l}\text { Time (min to establish alertness } \\
\text { *(mean士SEM) }\end{array}$ & $5.6 \pm 0.52$ & $7.7 \pm 0.68$ & $10.8 \pm 0.86$ \\
\hline \multicolumn{4}{|l|}{ Number of patients fully awake at } \\
\hline $1 \mathrm{~min}$ & $5 / 20$ & $4 / 20$ & $0 / 19$ \\
\hline $5 \mathrm{~min}$ & $19 / 20$ & $18 / 20$ & $12 / 19$ \\
\hline $10 \mathrm{~min}$ & $20 / 20$ & $20 / 20$ & $17 / 19$ \\
\hline $20 \mathrm{~min}$ & & & 1919 \\
\hline
\end{tabular}

*All pair-wise comparissns, i.e., A vs E, A vs F, F vs E, are significantly different using the Mann-Whitney U.Test, with adjustment of the critical $p$ value according to Ryan to maintain an overall experiment-wise enror rate of $0.05^{4}$ 


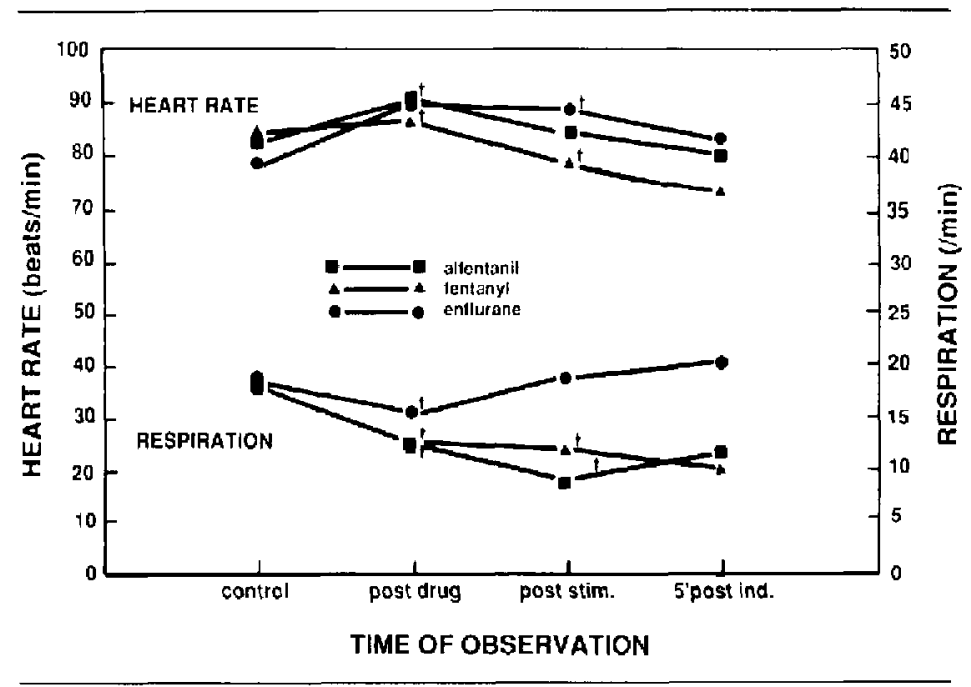

FIGURE 2 Heart rate and respiratory rate (†indicates significant change from control).

mask until spontaneous ventilation resumed at the end of the procedure. The second patient also moved at the start of surgical stimulation and was given more thiopentone without effect. When further alfentanil was given, chest wall rigidity and apnoea ensued which required succinylcholine administration to allow manual ventilation. Postoperative adverse events consisted mainly of nausea and vomiting. Overall, significantly more patients in Group A (55 per cent) had either intra- or postoperative adyerse events compared with only 15 per cent in Group F.

\section{Discussion}

As economic and social pressures are encouraging a shift toward day-care surgery from in-hospital surgery, the effects of the anaesthetic agents used should be predictably short and have minimal side effects. Alfentanil is a less potent derivative of fentanyl, with similar pharmacology but a faster onset and shorter duration of action. ${ }^{8.9-11}$ It has a greater total body clearance, a smaller volume of distribution and a shorter $t_{1 / 2}$ than either fentanyl or sufentanil. It is this faster elimination and shorter duration of action which makes it attractive as a supplement to outpatient anaesthesia. In this study, we demonstrated that the use of alfentanil as an adjunct to thiopentone; $\mathrm{N}_{2} \mathrm{O} / \mathrm{O}_{2}$ anaesthesia produces a satisfactory anaesthetic state in most patients and results in faster recovery with respect to time to respond to verbal commands and to establish alertness, as compared with the fentanyl $/ \mathrm{N}_{2} \mathrm{O}$ and enflurane $/ \mathrm{N}_{2} \mathrm{O}$ anaesthetics.

Cardiovascular stability has been an important benefit with the use of fentanyl and its derivatives. ${ }^{13-17}$ All anaesthetics as used in this study resulted in a decrease in systolic blood pressure while heart rate decreased significantly only in the group receiving fentanyl. None of the changes was clinically important.

Nausea and vomiting continue to be a major problem in the outpatient setting. The incidence of this particularly unpleasant side effect is still quite high ( 25 per cent) with alfentanil as used in our study. These numbers are similar to previous findings. ${ }^{14,15}$ Of interest is that the group

TABLE III Adverse events

\begin{tabular}{llll}
\hline & Alfentonil & Fentanyl & Enflurane \\
\hline Chest wall rigidity & $3(15 \%)$ & 0 & 0 \\
Apnoea & $3(15 \%)$ & 0 & 0 \\
Movement & $2(10 \%)$ & $3(15 \%)$ & $2(10 \%)$ \\
Coughing & 0 & $1(5 \%)$ & $3(15 \%)$ \\
Bronchospasm & 0 & 0 & $1(5 \%)$ \\
Laryngospasm & $1(5 \%)$ & 0 & 0 \\
\hline
\end{tabular}


receiving enflurane had only a ten per cent incidence of nausea and vomiting while no patients in the fentanyl group experienced nausea and vomiting. This observation cannot be readily explained since most other investigators have found at least a similar or higher incidence with fentanyl. ${ }^{9}$ Perhaps the combination of low-dose droperidol and fentanyl is important in producing this effect. Our observations should be confirmed in further studies.

We found that alfentanil caused chest wall rigidity and gross limb and body movement, which has been previously described in patients not receiving neuromuscular blocking drugs. The problem of chest wall rigidity can be minimized by a very slow injection of the drug. Although movement during these types of procedures is a common occurrence, it did not interfere with the surgery or pose a significant problem in any case. None of the patienits was aware during the procedures with any technique.

In summary, we found no significant differences among the groups with respect to ease of anaesthetic induction, dose of induction agent (thiopentone), amnesia, postoperative pain or patient/anaesthetist satisfaction. Overall, significantly more patients in the alfentaniltreated group experienced either intra- or postoperative adverse events when compared with fentanyl-treated patients. The main problems intraoperatively were related to chest wall rigidity, and nausea and vomiting accounting for the postoperative problems. On the other hand, those same patients recovered significantly faster than patients in either of the other groups. The patients who received the fentanyl/ $\mathrm{N}_{2} \mathrm{O} / \mathrm{O}_{2}$ anaesthetics had the fewest side effects, notably a complete absence of postoperative nausea and vomiting and still achieved a rapid recovery.

The singular benefit of a rapid recovery may not be enough to promote alfentanil over fentanyl or enfluranc, as used in this study, as adjuncts to $\mathrm{N}_{2} \mathrm{O}$ /thiopentone for outpaticnt surgery.

\section{References}

1 Paston CM, Moon MR, Dannemiller FJ. The prophylactic antiemetic effect of droperidol. Anesth Analg 1974; 53 : $361-4$.

2 Iwamoto K, Schwarlz $H$. Antiemetic effect of droperidol after ophthalmic surgery. Arch Ophthalmol 1978; 96 : 1378-9.

3 Rita L, Goodarzi M, Seleny F. Effect of low-dose droperidol on postoperative vomiting in children. Can Anaesth Soc J 1981; 28: 259-62.

4 Ryan $T$. Significant tests for multiple comparisons of proportions, variances and other statistics. Psychol Bull 1960; $57: 318-28$
5 Kay B, Venkataraman $P$. Recovery after fentanyl and alfentanil in anaesthesia for minor surgery. Br J Anaesth 1983; 55: $169 \mathrm{~S}$

6 Patrick $M$, Eagar $B$, Tof DF, Sebel PS. Alfentanil supplemented anaesthesia for short procedures: a doubleblind comparison with fentanyl. Anaesthesiology 1983; 59 : A346.

7 Sinclair ME, Cooper GM. Alfentanil and recovery. Anaesthesia 1983; 38: 435-7.

8 Patrick M, Eagar BM, Toft DF, Sebel PS. Alfentanilsupplemented anaesthesia for short procedures. $\mathrm{Br} \mathrm{J}$ Anaesth 1984; 56: 861-5.

9 Bidabe AM, Floras P, Gin AM, Dartiques F, Sabathie M, Caille $M$. Alfentanil as a supplement to neuroradioanaesthesia. Comparison with Fentanyl. J Neuroradiology $1985 ; 12: 191-9$

10 Antonios WRA, tnglis MO, Lees $N W$. Alfentanil in minor gynaecological surgery: use with etomidate and a comparison with halothane. Anaesthesia 1984; 39: 812-5.

11 Coe $V$, Shafer $A$, White $P F$. Techniques for administering alfentanil during outpatient anaesthesia - a comparison with fentanyl. Anaesthesiology 1983; 59: A347.

12 Reitz $\mathrm{J}$. Alfentanil in anaesthesia and analgesia. Drug Intelligence and Clinical Pharmacology 1986; 20: 335-41.

13 Kay B, Cahen AT, Shaw F, Healy TE.l. Anaesthesia for laparoscopy: alfentanil and fentanyl compared. Annals of the Royal College of Surgeons of England 1983; 65: 316-7.

14 van Leuwen $L$, Deen $L$. Alfentanil, a new, potent and very shart-acting morphinomimetic for minor operative procedures. Anaesthetist 1981; 30: 115-7

15 Kay B, Stephenson DK. Alfentanyl (R39209): initial clinical experience with a new narcotic analgesic. Anaesthesia 1980; 35: 1197-1201.

16 Bovill JG, Sebel PS, Blackburn CL, Heykants J. The pharmacokinetics of alfentanil (R39209): a new opioid analgesic. Anaesthesiology 1982; 57: 439-43.

17 Palazzo MGA, Taylor S, Strunin L. Clinical experience with alfentanil for the induction of anaesthesia; a comparison with thiopentone. Can Anaesth Soc J 1984; 31: 517-22. 


\section{Résumé}

On a comparé deux techniques anesthésiques atilisant des narcotiques avec protoxyde d" azote et une technique utilisant de l'enflurane protoxyde d' azote chez 59 parientes externes devant subir des procédures gynécologiques de courte durée. Toutes les patientes ont reçu du dropéridol $0.625 \mathrm{mg} V$, du thiopentone et 70 pour cent de protoxyde d'azote dans l'oxygène et soit de l'alfentanil $\left(15 \mu \mathrm{g} \cdot \mathrm{kg}^{-1}\right)$, du fentanyl $\left(1.5 \mathrm{mg} \cdot \mathrm{kg}^{-1}\right)$ ou de l'enflurane. Les narcotiques ont été donnés à double insu et les rechniques anesthésiques d' inhalation furent randomisées. Les paramètres cardiorespiratoires sont demeurés stables chez toutes les patientes dans les trois groupes et pew de changements cliniquement importants sont survenus. La récupération était significativement plus rapide chex le groupe ayant reçu de l'alfentanil avec un temps de réponse à la commande verbale significativement plus court que celui du fentanil ou de l'enflurane. Touter Les techniques ont fourni une anesthésie satisfaisante. Cependant le groupe ayant reçu de l'alfentanil avait significativement plus d' cffets secondaires que celui ayan reçu de fentanyl. 